RESEARCH ARTICLE

\title{
Students as Partners in Collaborative Course Design and Educational Research
}

\author{
Cortney Hanna-Benson, Shayla Kroeze, Radhika Gandhi, Tom Haffie, and *Lindi M. Wahl, \\ University of Western Ontario, Canada. \\ Contact: Iwahl@uwo.ca
}

\section{ABSTRACT}

The impact of collaborative course design is explored in this qualitative, longitudinal study of an upper-year course in which 30-40 undergraduate students co-designed the course syllabus, including both course content and assessments. In addition, the research questions and methods were co-designed by a research team involving six undergraduate student partners, an educational developer, and two faculty members. Student written work and focus-group transcripts were coded and analyzed using longitudinal interpretive phenomenological analysis. The two major themes emerging from this analysis were (a) growth (i.e., the development of academic skills, reflective practice, and personal growth that extended beyond the course), and (b) awareness (of students as a community of learners, of instructors as partners in learning, and of personal agency in learning). Personal reflections on the impact of this partnership revealed broad benefits to both students and academic staff.

KEYWORDS

collaborative course design, syllabus design, phenomenological analysis

The manifest advantages of student-staff collaboration in higher education, illustrated through such examples as peer instruction (Vickrey, Rosploch, Rahmanian, Pilarz, \& Stains, 2015), supplemental instruction (Dawson, van der Meer, Skalicky, \& Cowley, 2014), collaborative testing (Gilley \& Clarkston, 2014), and student-generated questions (Kay, Hardy, \& Galloway, 2019) are well-documented. Within this context, the Students-as-Partners (SaP) movement seeks to broaden opportunities for students as co-instructors (Held \& Rosenberg, 1983) and educational consultants (Lesnick \& Cook-Sather, 2010) and for engaging learners as co-producers rather than consumers of course content (McCulloch, 2009). In particular, students are supported as co-designers, co-developers, and co-instructors with academic staff, working together on a wide variety of educational projects (Cook-Sather, 2014; Healey, Flint, \& Harrington, 2014). 
One particularly rich opportunity for creative partnerships between students and instructors arises in collaborative course design. In many examples, senior students who have successfully navigated a particular course may work to re-design the course for a future cohort in one-on-one partnerships (Bovill, 2014; Hufford, 2011), in faculty-student teams (Bovill, 2014; Cordner, Klein, \& Baiocchi, 2012; Mihans, Long, \& Felten, 2008), or with academic developers (Bovill, Cook-Sather, \& Felten, 2011). Feedback on such re-designed courses is overwhelmingly positive (Cordner et al., 2012; Hufford, 2011; Mihans et al., 2008), and both students and staff report that involvement in these design partnerships increased their engagement, enthusiasm, and pedagogical understanding (Bovill et al., 2011).

Collaborative course design between instructors and students who are currently enrolled in a course entails further challenges but can offer unique rewards in terms of student ownership and empowerment. Instructors may involve students in negotiating course policies and expectations (Shor, 1997), for example, by allowing students to offer input and amendments to a proposed syllabus (Hess, 2008; Moreno-Lopez, 2005). Students may develop the content for a single unit or class session (Glenn, 2003; Taylor \& Bovill, 2018) or may determine the content topics for an entire course (Bovill, 2014). In introductory courses with little flexibility in content, students may design the grading contract (Moreno-Lopez, 2005) or design the entire assessment structure for the course (Hudd, 2003).

More rarely, collaborative course design can "start with the syllabus," (Blinne, 2013) such that course topics, learning outcomes, activities and assessments are all negotiated and co-designed with current students, turning an essentially blank course outline into a jointlyconstructed syllabus over the course of, typically, the first several class sessions. Examples include the co-design of a graduate journalism course (Chen et al., 2001), a graduate pedagogy class (Fassett \& Warren, 2006), and an undergraduate experiential-learning summer course (Hains \& Smith, 2012). While these examples typically involved co-creation of low-enrollment courses (10 students or fewer), Brubaker (2012) explores authority in the classroom through the collaborative design of a required teacher education course involving 22 undergraduates. Similarly, Jafar (2016) reported that the process of co-designing the complete syllabus for a mid-level sociology course increased engagement, empowerment, and accountability for the 18 undergraduates in the course.

Although the effects of co-designed syllabi are difficult to isolate in a controlled study, Holt and Willard-Holt (1995) describe their unique experience in offering three graduate education courses to 56 students in total. All three classes were given the option of using an instructor-created syllabus or creating their own course; two of the three classes chose the latter option. This study thus allowed for a powerful comparison between similar classes and instructors within the same context; students reported greater ownership, involvement, and an increased sense of accomplishment in self-designed courses, whereas measures of academic achievement in the three courses were similar (Holt \& Willard-Holt, 1995).

Thus, to date, only a handful of publications describe the process of collaborative design of all aspects of a course by students currently enrolled in the course; those that do focus on relatively low enrollment or graduate-level courses, and rarely (if at all) have undergraduate students been engaged as co-investigators and co-authors in researching the impact of this approach. This apparent gap in the literature set the stage for our work. 
We explored the impact of collaborative course design in a qualitative, longitudinal study of an upper-year elective course involving 30-40 undergraduate science students. A unique aspect of our work is that the research questions and methods were co-designed by a research team involving six undergraduate student partners, an educational developer, and two faculty members; two of these student partners were able to continue their involvement throughout the data analysis and interpretation of the research and are co-authors of this research contribution. While discipline-specific research experiences for undergraduates are well-studied (Bauer \& Bennett, 2003), students are less often invited to contribute in the design of pedagogical research (Healey et al., 2014; Maunder, Cunliffe, Galvin, Mjali, \& Rogers, 2013). In this contribution we offer longitudinal results on the impact of collaborative course design, as well as personal reflections, by both the faculty and student authors of this research study, regarding our experience of this partnership in pedagogical research.

\section{COLLABORATIVE COURSE DESIGN PROCESS}

The course in question, a third-year one-semester elective offering called University Science Education, was offered in an active learning classroom with students organized into "pods" of six students each: seven pods in the initial cohort (January-April 2018) and six pods in the second cohort (September-December 2018). We used the same collaborative course design approach in both cohorts. In particular, the first class of each term opened with a syllabus providing only basic administrative information and the following broad educational goals:

- Establish a reflective practice that deepens awareness of personal experiences of learning and teaching.

- Increase skill with evidence-based strategies for effective education.

- Increase awareness, and critical analysis, of educational literature.

- Expand command of disciplinary knowledge in science.

- Facilitate positive change beyond the traditional boundaries of the course.

During the first three weeks, two faculty facilitators collaborated with students within an appreciative inquiry framework to develop learning outcomes, learning activities, assessments, due dates, and course policies. Broadly speaking, appreciative inquiry is an approach to organizational development that uses generative questioning to focus attention on, and raises the value of, positive aspects of an organization/system/process under study (Cockell \& McArthur-Bain, 2012). An appreciative inquiry typically poses questions such as, "Which aspects of this system are working particularly well? How can such positive deviance be enhanced or expanded? What does this system need more of?" Data collected through interviews among various stakeholders are collated and used as a basis for collaborative generation of accountable action plans. We developed our course design process around the five-stage appreciative inquiry model (defining, discovering, dreaming, designing, and delivering) of Cooperrider, Whitney, \& Stavros (2005).

In the Defining Phase, students were invited to conduct reciprocal appreciative interviews with a classmate in which they identified and explored those aspects of their educational experience that had been most effective. Each student submitted an anonymized 
summary of their interviewee's responses. In the Discovering Phase, each pod of students reviewed a different collection of up to 10 interviewee summaries with the goal of identifying three "big ideas": recurring themes and/or innovations and/or insights that could be relevant to our course design process. In the Dreaming/Designing Phase, students expanded their awareness of evidence-based practices in post-secondary education by reading in the scholarship of teaching and learning (SoTL) literature (as guided by topics and articles recommended by academic staff). Then pods engaged in a creative exercise to imagine learning outcomes, activities, assessments, and policies that might be included in the course. These ideas were eventually each pitched graphically in a poster format to the entire class for voting. This Dreaming/Designing Phase also included an exercise that enabled students to identify specific content areas that they thought were important to study.

During the final Delivering Phase, academic staff facilitators gathered and synthesized all student input, proposing a collaborative syllabus that constructively aligned student-generated outcomes, activities, and assessments in a learning environment that also respected university regulations and timetables. The proposed syllabus was presented to students who were invited to discuss it in the absence of academic staff and post an online critique. A final, modified, syllabus was then proposed by the facilitators and formally adopted by the class. Throughout all stages of the appreciative inquiry design process, an online forum was open on the university's learning management system as a venue for students to post anonymous comments, ideas, or concerns that may have otherwise been overlooked.

We appreciate that collaborative course design may raise concerns for instructors who might be nervous about negotiating control over such traditional faculty responsibilities as selecting course content, managing classroom dynamics, and ensuring both academic rigour and respect for institutional policies. Although the assessment structures in our course were student-generated, we emphasize that throughout the academic term, faculty facilitators created rubrics to establish word counts and due dates, to emphasize critical analysis, and to otherwise define expectations for academic rigour. Facilitators also assumed responsibility for the creation of a final exam, all summative evaluation of student work, presentation of several content topics, and ongoing academic support for students working within an unfamiliar course structure.

\section{RESEARCH METHODS}

\section{Design of the research project with student collaborators}

The process of research design began by inviting all students from the initial cohort to join a research team. This team then worked alongside academic staff to develop a research protocol exploring the impact of the collaborative design process as experienced by the second cohort.

The research team met to reflect on the impact and personal experiences within the initial offering of the course. These experiences included, but were not limited to, how the course impacted students as learners and educators, changes in motivation throughout the course, and the course's impact on subsequent classes taken by students. As a result of the 
conversation, the research team generated five questions that served as the focus for the study of subsequent offering of the course (Table 1).

\section{Table 1. Research questions}

1. Did the course, in any way, increase self-awareness as a learner and science student?

2. What were the changes in attitude experienced by the students from the beginning of the course in comparison to the end?

3. Did the collaborative aspect of the course have any impact on how students approached other classes?

4. How did engagement in the course and course assessments change in response to the collaborative course design process?

5. How does a student-designed course differ from a fixed syllabus course?

The questions posed by the research team were investigated via two methods: written coursework, which was assigned intermittently throughout the semester, and focus groups following the completion of the course. For the written coursework, the research team designed questions that they hoped could be included in the second offering of the course, subject to the course structure (as yet undecided by the second cohort of students). We note that one constraint in syllabus design was the official designation of the course as an "essay course" by the university administration. To meet this criterion, substantial written work must be included in student assessment; thus, we had reason to believe that questions designed by the research team could be included in the second offering of the course.

To augment the qualitative methods described above, the research team also administered two established quantitative survey tools. The Science Motivation Questionnaire II (Glynn, Brickman, Armstrong, \& Taasoobshirazi, 2011) is a 25-question survey scored on a Likert scale that measures five aspects of student motivation: intrinsic motivation, selfdetermination, self-efficacy, career motivation, and grade motivation. This survey was administered in class during the first week of the semester and then once again during the final week. The Student Course Engagement Questionnaire (Handelsman, Briggs, Sullivan, \& Towler, 2005), a 23-question survey measuring student engagement in a single course, was administered in class during the final week of the course. All students received nominal participation points for completion, regardless of their participation in the study. Survey questions are available in Table 1 of Glynn et al. (2011) and Table 1 of Handelsman et al. (2005) respectively.

\section{Final course structure}

The final course structure differed between the two class cohorts. We report here the composition of the second offering of the course, relevant for the research study to follow. The first offering of the course included a similar mix of individual written work, presentations, group work, and reflections, but with differing emphases and topic choices. 
Students in the second cohort opted to learn more about the existing literature in the scholarship of teaching and learning by writing four "Mini Papers" which critically assessed pedagogical journal articles chosen by the faculty team. The students then applied various evidence-based teaching methodologies encountered in the literature to their own in-class teaching assignments. In an assessment entitled "Ladder to Learning," students each facilitated learning of a science topic of their choice at the Grade 1, Grade 7, or introductory university level, while considering limitations such as class sizes, in-class resources, mandated science curricula, and the cognitive capacity of their audience. This assessment also included a followup written summary. Another in-class teaching assessment was a classroom facilitation; this group project involved teaching a scientific topic at the university level while employing active learning techniques and promoting inclusivity and accessibility for a diverse group of learners. This assessment included individual preliminary explorations of relevant literature as well as a final written group report.

Students also wrote several personal reflections in response to prompts provided by the faculty team. This reflective practice encouraged students to consider their personal growth and how experiences in the course may have "rippled out" into their academic life. As well, students were challenged to demonstrate metacognitive awareness of the course participatory design and how this may impact their overall approach in the sciences. Students ended the term by completing a take-home final exam which involved answering several essay-style questions. These questions challenged students to come up with strategies supported by current literature to improve learning in university classes and encouraged them to produce their own creative solutions. Students also included a final reflective piece about their personal transformation throughout the course.

\section{Written work}

The research team was able to use three of the weekly reflection prompts to address major themes outlined by the questions in Table 1 :

- Reflection \#1 (beginning of course): In roughly 250 words, write a message to your future self that shows awareness of the areas in which you hope to grow or change over the time you are in this course. Be sure to attend to affect; how does it feel to anticipate this change?

- Reflection \#2 (midway through course): In roughly 250 words, reflect on how your experiences in this course "ripple out" in your academic life. In what ways are you different outside this course that you can trace back to your experiences inside the course? Include a specific example if appropriate. Be sure to attend to affect; what is the emotional content of these ripples?

- Reflection \#3 (final week of course): Re-read your response to Prompt \#1 in which you identified ways in which you anticipated changing over your time in this course. In roughly 300 words, reflect on your experience in a way that shows awareness of how you have grown or changed as a result of your myriad experiences in this course. Include a specific example if appropriate. Be sure to attend to affect; how do you feel as your mind replays your experiences? 
Similarly, the research team was able to include a final examination question which addressed the topic of metacognition and the impact of a co-designed curriculum on students' approach to their science education:

- Reflection \#4 (final exam component): Recall that "metacognition" refers to thinking about your thinking. In the context of this question, metacognition refers to thinking about your learning and growth as a student of science. One of the unique features of this course was the process of course design in which you were an active participant. How has your experience of this collaborative, participatory design process affected your overall approach to your education in science? How did the process of designing this course affect aspects of your practice such as your academic skills, attitude toward your studies, relationship to faculty, self-confidence or motivation, future plans, etc.?

\section{Focus groups}

Following the completion of the course, focus groups were facilitated by a research assistant who had no prior contact with the students nor influence on the course grades. The facilitator used an appreciative inquiry approach that invited students to identify aspects of their experiences that were particularly meaningful. Focus group discussions were recorded, transcribed, and subjected to thematic analysis as described below.

\section{Qualitative research methodology}

This research was qualitative in nature, gaining an in-depth perspective of students' experiences with the collaborative course design. The responses to four reflections submitted as a course component, in addition to focus-group data, served as the research materials for this study. The focus groups were semi-structured, allowing the focus-group facilitator to gain a deeper understanding of the context in which the participants described their experiences throughout the course, while also exploring their responses in depth as the opportunity arose.

Fifteen students consented to participate in this study. Their participation involved granting the data analyst permission to view the coded responses to their reflections and linking their responses over time while maintaining anonymity. The written course materials and focus-group transcripts from consenting students were de-identified, coded, and subjected to longitudinal interpretive phenomenological analysis (IPA). Longitudinal qualitative research "focuses on individual narratives and trajectories and can capture critical moments and processes involved in change" (Calman, Brunton, \& Molassiotis, 2013, p. 1). Specifically, longitudinal interpretative phenomenological analysis explores not only the lived experience of having gone through this course, but also how students made sense of it over time. Accordingly, this method chosen is suitable for identity change processes (Smith, 2011).

Data were analyzed following Smith, Flowers, and Larkin's (2009) six steps for interpretative phenomenological analysis. The longitudinal component involved an additional step in the analysis that looked at how the themes were expressed across individuals over time. Figure 1 presents an overview of the longitudinal IPA data analysis conducted on the linked reflections. This type of analysis is consistent with previous studies employing longitudinal IPA 
(e.g., Smith, 1994; Spiers, Smith, \& Drage, 2016; Thomson, Martin, \& Sharples, 2017). The focus groups were analyzed using Smith and Osborn's (Smith \& Osborn, 2008) interpretative phenomenological analysis which involved developing and applying codes (i.e., open, axial, and selective coding), then identifying themes, patterns, and relationships. Due to the nature of the data collection process, focus-group participants' data were not linked to their previous reflection responses. Instead, the focus-group analysis provided insight into the contextual factors in play throughout the study. We also note that the data analyst, who coded and analyzed both focus-group transcripts and written work for this study, was not involved in designing the research study nor aware of the proposed research questions until after the completion of this analysis.

Figure 1: Flowchart of data analysis following Smith, Flowers, and Larkin's (2009) process for longitudinal interpretative phenomenological analysis

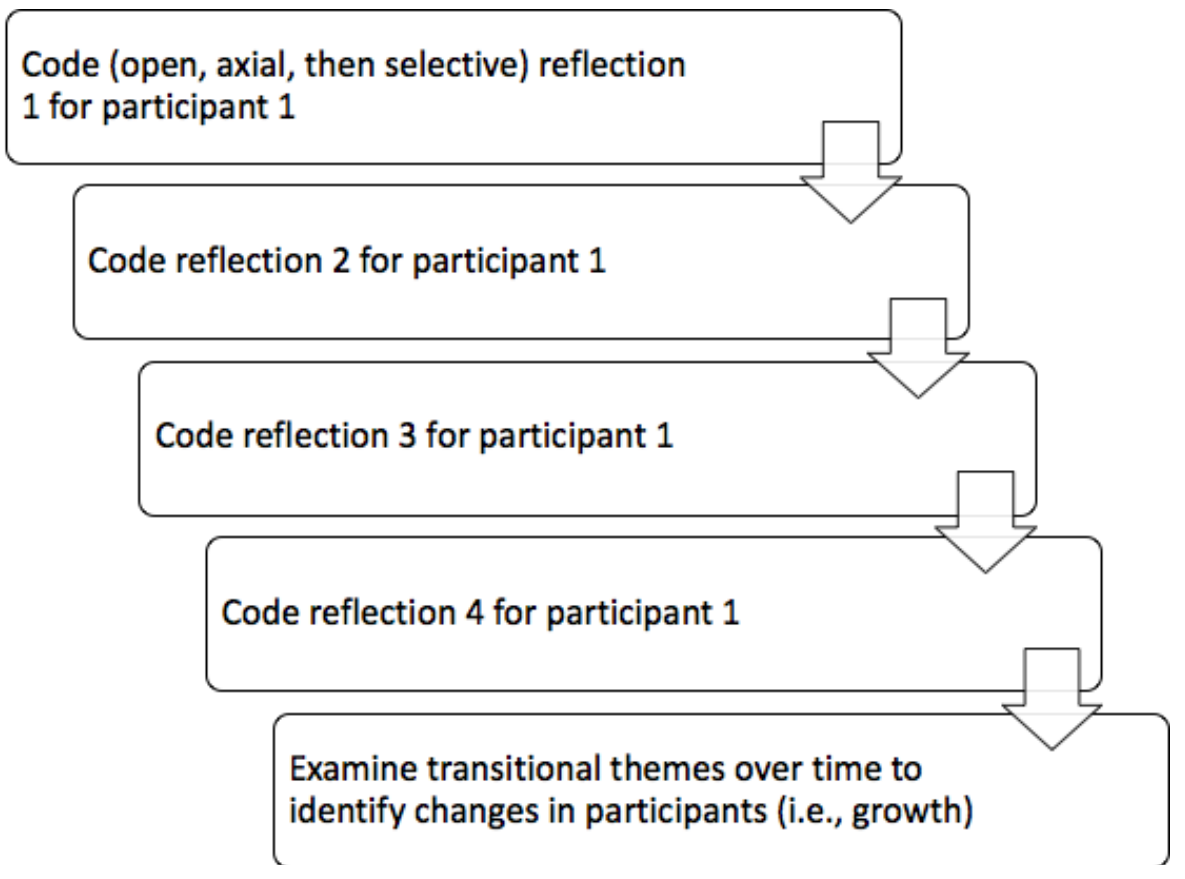

\section{RESULTS AND DISCUSSION}

\section{Quantitative results}

Overall, the quantitative results of our study did not show any statistically significant trends; we include the results and their statistical analysis here for completeness, and discuss some of the factors that may have influenced this outcome in the paragraphs to follow.

Sixteen students completed all three surveys and granted permission for the use of their pre- and post-semester responses to the Science Motivation Questionnaire II (SMQII, Glynn et al., 2011) and their post-semester responses to the Student Course Engagement Questionnaire (SCEQ, Handelsman et al., 2005); of these 16 students, 14 correctly completed 
their unique anonymized identifiers in the post-semester survey such that their pre- and postsemester responses could be matched and compared.

In the SMQII, responses to survey questions range from 0 ("never") to 4 ("always"). Figure 2 shows the mean response to each question in the pre- and post-semester surveys (circles and crosses, respectively, left panel), along with the difference between these mean values (centre panel). Dashed lines give the $95 \%$ confidence interval for the magnitude of this difference that would be expected by chance (described below). Thus, responses to none of the SMQII questions changed significantly pre- versus post-semester.

To assess this statistical significance, we used a bootstrap approach. We pooled all survey responses (across questions, students, and pre- and post-semester surveys) to obtain the total number of " 1 " $s$, " 2 "s, etc., in the dataset. We then re-assigned these responses randomly to the 25 questions, 14 simulated students, and the two survey times. Finally, we computed the mean difference between pre- and post-semester mean response to each question in the randomized data. We repeated this random permutation process for one million permutations. The right panel of Figure 2 shows the distribution of post- versus presemester differences that occur by chance in our dataset. Dashed lines show the $95 \%$ confidence interval (including the necessary Bonferroni correction for simultaneously testing 25 results for significance). At the top of the figure, we show the mean post- versus pre-semester difference in the actual survey data we obtained (blue circle, mean of data points in centre panel), error bars showing one standard deviation about this mean (bold blue line), and the full range of the differences in the data we obtained (thin blue line, range of data points in centre panel).

\section{Figure 2: SMQII results}
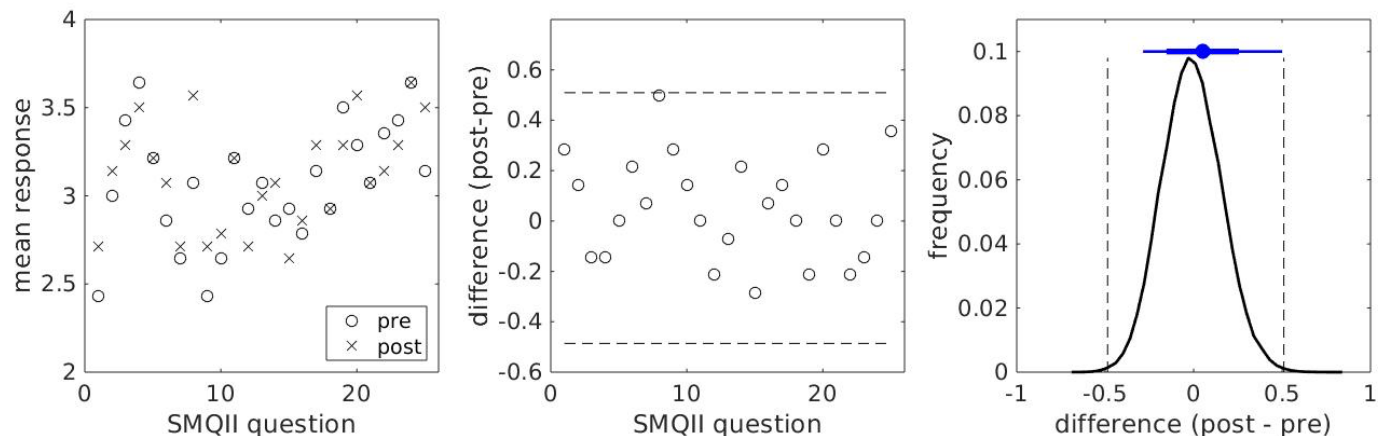

The mean response to each question in the pre- and post-semester SMQII surveys (circles and crosses, respectively, left panel), along with the difference between these mean values (centre panel). Dashed lines (centre panel) give the $95 \%$ confidence interval for the magnitude of this difference that would be expected by chance. The distribution of post- versus pre-semester differences that occur by chance, as determined by stochastic bootstrapping, is shown on the right. Dashed lines show the $95 \%$ confidence interval (including a Bonferroni correction for simultaneously testing 25 results). The mean post- versus pre-semester difference in the actual survey data we obtained (blue circle, mean of data points in centre panel), error bars showing one standard deviation about this mean (bold blue line), and the full range of the differences in the data we obtained (thin blue line, range of data points in centre panel) are shown at the top of the panel for comparison. 
In the SCEQ, responses to survey questions range from 1 ("not at all characteristic of me") to 5 ("very characteristic of me"). Figure 3 shows the mean response to each question, averaged across students (left panel), and the mean response of each student, averaged across all questions (right panel). Filled circles and error bars on the right of each panel give the mean value of the data presented in that panel, plus/minus two standard deviations, corresponding to a $95 \%$ confidence interval. Again, none of the survey questions was significantly different from the others, nor did particular student responses differ significantly from the average response of participants.

\section{Figure 3: SCEQ results}
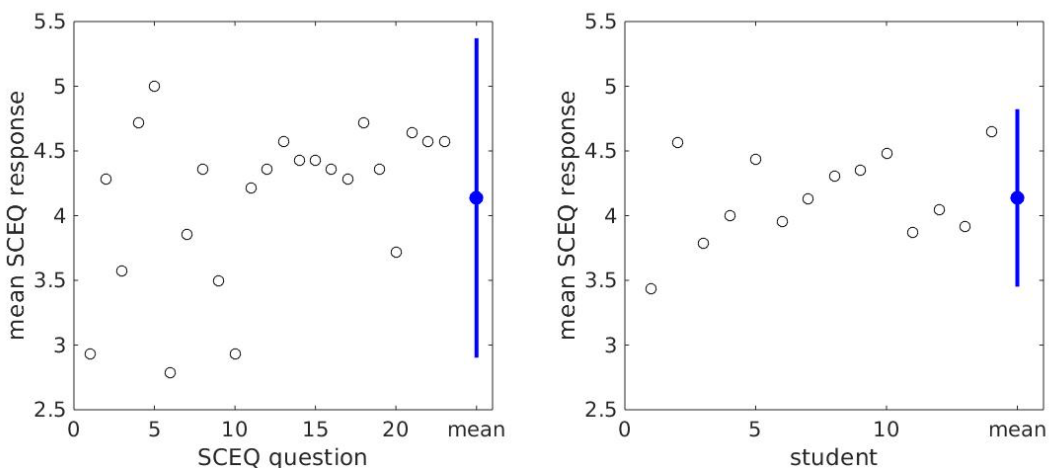

The mean response to each question, averaged across students (left panel), and the mean response of each student, averaged across all questions (right panel). The mean of the data presented in each panel, plus/minus two standard deviations ( $95 \%$ confidence interval) is shown for comparison (blue circle, error bar).

In summary, neither of the established survey instruments we employed yielded statistically significant results in this study. It is possible that a more nuanced statistical analysis, considering the distribution of responses (numbers of " 1 " $s$, " 2 " $s$, etc.) rather than simply the mean response for each question or student, might reveal statistically robust trends in these data. Our results were limited by the relatively small number of participants who completed both surveys, granted permission for their use in the research study, and correctly provided their unique anonymized identifier in the post-semester survey, such that pre- and postsemester survey results could be compared. In addition, given the self-selected group of highly motivated and engaged students who enrolled in this non-required course, it seems likely that neither of these survey tools was sufficiently discriminatory to detect differences within our relatively small but highly engaged study group.

\section{Qualitative results}

Student responses clustered around two major themes of (a) "growth," expressed as willingness to confront and learn from personal and/or academic challenges and (b) "awareness," expressed as a change in students' understanding of the science classroom, course, and instructor, as well as a new awareness of their own learning process. Four subthemes emerged within each of these themes. These themes and subthemes are expanded upon below, highlighting impactful quotes from students' reflections, and summarized in Table 2. 


\section{Growth}

The many learning activities throughout the course granted students the opportunity to refine desired academic skills. The skills identified by students included: critical thinking, writing, presentation, creativity, time management, collaboration, and communication, reflexivity, and general learning skills. Students sought to refine these skills and felt accomplished when they reflected upon their progress. Participants who considered themselves to be shy or who struggle with public speaking felt this class granted them a "safe space" to improve upon this skill. Consider the following quotes from a student at the beginning of the course, contrasted with their response towards the end of the course. In their first reflection, the student wrote:

"One major thing I'm really hoping to work on during the course is my presentation skills. I often become flustered when giving a presentation, by the end of the course I hope to become more comfortable when speaking." The student reported meeting this goal in Reflection \#3:

My one goal was improving presenting skills and becoming more comfortable presenting. I feel confident that I achieved that goal. I am by no means an incredible presenter/speaker, but I have felt improvement. Just last year I remember shaking nervously and even almost crying during a presentation. In contrast, I felt good presenting with my facilitation group.

Students also expressed growth experienced through the process of reflecting. In doing so, they recognized that their initial version of reflexivity was superficial. In engaging in selfreflection, students also recognized the role their emotions play in their writing and learning. Students discussed their previously held beliefs that information should only be presented factually and logically. Incorporating reflection into their scholarly activities allowed them to link their emotions to critical thinking.

In a third area of growth, students forced themselves to operate outside of their comfort zone. In doing so, they became more comfortable and confident. In reflection on previous courses, most often, students related the lack of comfort in participating or engaging in class to the worry of being wrong or being scrutinized by their peers or professors. For example, one student described their fears surrounding participation in their first reflection:

I can see myself overcoming the fear of participating in group discussions before knowing the "right" answer. ... It may be a fear of being wrong or a feeling of wasting time, but I know that many times, I found myself missing the entire opportunity because I hesitated and contemplated for too long and that did not feel good."

The same student reported increased confidence in a later reflection:

Through the many opportunities to collaborate with my pod, the class, and my group members, I have gotten more comfortable in sharing my opinions and ideas. I've 
realized that my fears of not being right were not really valid fears because even if I wasn't "correct," it didn't really matter. Rather it stimulated more discussion. I feel more confident in pitching in ideas and it feels nice to see many of those be considered in group work.

Finally, participating students recognized their progress and growth throughout the course but were mindful that their growth continues beyond the course. They expressed the desire to apply new approaches to their learning beyond the course itself. Many expressed that this course helped them elucidate the reasons, beyond grades, underlying their learning.

\section{Awareness}

For many participants, this course provided an opportunity for students to increase awareness of their roles as members of a community. They valued the experiences of their peers in approaching complex problems, either in conceptualizing the course components or in approaching problems in science. Students expressed seeing the value in the collaboration of individuals with a diverse background and skill set. The group work in this course is an effective precursor for teamwork in other courses and beyond into a professional setting. Voiced as a letter from the student to their self, one student described their experience in another course:

I noticed this change last week, in your biology tutorial, when you were working on a group project. Before the group divided the writing tasks, you stepped in and asked everyone to think about the intended audience. Then, as a group, you proceeded to talk about what kind of message you wanted the reader to receive and also what vocabulary range was appropriate. It felt great to take initiative and share this critical thinking strategy with your peers, something you wouldn't have done prior to taking Science 3450 .

The same student, in a later reflection, discussed new confidence in collaborative work:

Creating the course outline allowed me to bond with my peers and also my professors because we worked together towards a common goal. I was also given some opportunities of leadership in the group discussions when making the syllabus, and when my ideas were well-received, it definitely built confidence in my learning. This activity was also one of my few exposures to collaboration in university and really initiated my learning in group work throughout the semester.

Participants' preconceived notions of university courses were also challenged, increasing their awareness of pedagogical aspects of course design. Participants recognized the value of learning activities and assessments for skill development and left the course with a better understanding of course design as a procedure (i.e., there are many extraneous factors to course design). They can look back to their previous course experiences and newly understand the motivation for various learning activities implemented by previous instructors. 
Students recognize the importance of interactive learning activities but recognize the barriers for implementation in larger classes.

Participating students also changed their awareness of course instructors, beginning to conceptualize the role of instructor as simultaneously partner, facilitator, and learner, and thus breaking down assumed barriers to communication.

Finally, empowered by the experience in selecting learning activities, students became increasingly aware that learning is under their control. Energized by the prospect of picking their own assessments, students reported being excited about school, a feeling they had not experienced for some time. They immersed themselves in the learning experience and appreciated how welcoming it felt to be invited to help shape their own learning environment. One student described their increased sense of personal agency in learning as follows:

After looking at the Kolb Learning styles, I wanted to become more emotional (in a positive way!) towards my education. For example, any course I took this semester, I tried to approach it in a way that made me want to learn. I got myself to feel excited about the material I was learning.

Later in the course, the same student reflected:

Looking back on my semester, I realized how much this transcended into my other courses. ... At the same time, I was understanding the content in my classes better than ever. I was enjoying the process of learning and continuously engaged in discussions about the material and my grades reflected this.

These themes and subthemes are summarized in Table 2.

Table 2. Major themes and subthemes that emerged from the longitudinal IPA based on participants' reflections and focus-group transcripts

\begin{tabular}{|l|l|}
\hline GROWTH & AWARENESS \\
\hline Development of academic skills & Awareness of class as community \\
\hline Development of reflective practice & Awareness of pedagogy in university teaching \\
\hline Expansion of "comfort zone" & Awareness of instructors as learning partners \\
\hline Continued personal growth beyond course & Awareness of personal agency in learning \\
\hline
\end{tabular}

Returning to the research questions posed at the outset of the study (see Table 1), we note that the first of the research questions queried self-awareness as a learner, while the second addressed changes in attitude from the beginning to end of the semester. Answers to these two research questions clearly emerged as the main themes, "growth" and "awareness," of the qualitative analysis. This correspondence between our research questions and the Hanna-Benson, C., Kroeze, S., Gandhi, R., Haffie, T. \& Wahl, L. M. (2020). Students as partners in 
emergent themes of the analysis is particularly compelling since the thematic analysis of written work and focus groups was performed blind to these research questions. The third research question, regarding the impact of the course beyond the classroom, emerged as the subtheme "continued personal growth beyond course," while the fourth research question, regarding the impact of collaborative course design on student engagement, was touched upon in many ways in the "awareness" theme, such as in students' increased awareness of pedagogy, of instructors as learning partners, and of personal agency in learning. In retrospect, our fifth research question, "How does a student-designed course differ from a fixed syllabus course?", was possibly too ambitious, but perhaps this research contribution as a whole can be seen as part of an answer that is emerging, globally, in this vibrant research area.

Theories of leadership development make a distinction between horizontal vs. vertical dimensions (Eigel \& Kuhnert, 2005; Petrie, 2014). That is, horizontal development involves the "what," or the growing command of specific content knowledge, skills, and habits of mind that characterize the practice of a particular role or discipline. Vertical development addresses the "how," or the growing ability to think in more wholistic, self-aware, integrated, and complex ways that in turn determines the strategies one chooses for effectively employing the specialized knowledge, skills, and habits of mind of a role or discipline.

In the context of higher education, traditionally content-heavy lecture-based STEM programs tend to be strongly, and often exclusively, oriented toward promoting horizontal growth of students. However, the themes of growth and awareness arising from analysis of student participation in this study highlight collaborative course design as a powerful platform for vertical development. Conditions that promote vertical growth, as summarized by Petrie (2015), typically involve situations that are initially challenging to one's self-image, skill sets, psychological comfort, beliefs, or values. If such an unsettling experience is followed by exposure to people with diverse perspectives, opinions, backgrounds, and expertise, then a range of novel avenues of understanding may become available. Follow-up feedback, reflection, and/or coaching can then help one to integrate diverse ideas and experiences into an expanded, more complex worldview.

In our course, the simple layout of the active learning classroom that seated students in pods of six was challenging to students' habitual approach to classroom environments. Students could not orient themselves toward any "front" of the room. Sitting face to face in pods created a space that was more intensively interpersonal than students typically experienced in other courses where everyone is facing the instructor. In addition to the unfamiliar physical and interpersonal conditions in this learning environment, the invitation to collaborate with peers and instructors on the course design was a novel educational process for every student in the course. All things considered, our appreciative collaborative course design model provided generative conditions for vertical development: unsettling situations interwoven with interaction with diverse opinions and ideas from peers, academic literature, and instructors, followed by opportunities for feedback, reflection, processing, and support from colleagues and instructors. In our experience, students responded with sustained enthusiasm to these opportunities to stretch themselves in ways that were otherwise lacking in their educational experience. Such responses from our students add to the growing literature 
confirming positive impacts of student-faculty collaborative course development efforts (Holt \& Willard-Holt, 1995; Cordner et al., 2012; Hufford, 2011; Mihans et al., 2008; Bovill et al., 2011).

\section{CRITICAL REFLECTION}

While the qualitative analysis above speaks to the impact of collaborative course design on students enrolled in the course, both instructors and students on the research team also experienced the project as a powerful vehicle for engagement. In the following subsections, we provide short reflections on the impact of the research process from a student perspective and the overall impact of the course from the perspective of course instructors.

\section{Personal experience of students involved on the research team}

Involving students as research partners allows for a mutually beneficial sharing of resources, in which academic staff benefit from a student's perspective while students benefit by gaining enhanced research skills (Maunder et al., 2013). This section will focus on the experience of the co-authors of this contribution who were students in the initial offering of the course and were later involved in the design of the research conducted during the subsequent offering.

As students, our involvement in the research process allowed us to apply many skills developed both in this course and in other aspects of our university education. Designing the research study required both reflection and critical enquiry in order to develop research questions that could test anecdotal experiences of learning. For example, research design made it necessary to reflect on how the use of collaborative course design in the classroom impacted our learning experiences, and how those experiences might be tested experimentally. Exploring how the student-centered environment enhanced learning and how the students in our class expressed this experience gave us a better understanding of how collaborative course design empowered us and continues to do so. Equally empowering was the opportunity to provide evidence that collaborative course design positively impacted our learning and has the potential to benefit students in the future. We believe that the first-hand experience of students provides unique insights into pedagogical research design that might not be achievable without students as research partners.

Our growth through this process reflects research by Bauer and Bennet (2003) which found that undergraduates who participated in research projects reported improved communication and research skills, as well as increased personal initiative. Additionally, working with staff members and fellow student partners in research provided mentorship in a way that is not typically accessible in the classroom. We suggest that involving students in pedagogical research design allows for authentic insight into the learning experience and provides unique opportunities for students to engage.

\section{Experience of course instructors}

For the instructors, the sense of student partnership and ownership was powerfully demonstrated during classroom sessions, making our own involvement in the course unusually rewarding. Unexpectedly, our participation as learners in student-led classroom activities 
broadened our awareness of educational resources/approaches and offered unique opportunities for critical reflection on our own teaching practice.

Working with the student team in research design also had unexpected benefits. Overall, the student team brought continued energy and enthusiasm as well as a refreshing sense of "newness" to the research project. Such increased engagement of students inspired and validated our educational practice. Specifically, the relationship offered us an opportunity for a novel type of mentorship, more akin to the authentic collaboration faculty typically have with their graduate students based on shared goals and responsibilities. This welcome but rather rare opportunity to mentor students around issues in education (rather than disciplinary research in science) was also noted by Cordner et al. (2012). Working with students also provided many opportunities to elaborate ideas and skills that had been introduced in the previous course.

The several challenges described in the literature associated with collaborative course design, including negotiations of power dynamics (Mihans et al., 2008), underlying unpredictability (Cordner et al., 2012), balancing student expectations and aspirations for the course with faculty concerns for managing their workload (Jafar, 2016), and ensuring academic rigour and respecting university regulations (Bovill et al., 2016), were also apparent in our experience.

In addition, our design presented the inherent limitation of timing: course preparation cannot be completed in advance of course design, and thus the workload for preparing classroom sessions, rubrics, and readings fell more heavily during the teaching term itself. Content delivery to support student-designed learning outcomes was often distributed among subgroups within the class; nonetheless some advance preparation by the facilitators was typically necessary, and this could only begin after the "content pieces" of the course had been identified. A challenge that emerged for the research design team was that the project naturally extended over a duration greater than one year, necessitating some turnover in the student team due to graduations and other commitments.

\section{CONCLUSIONS}

Our work provides evidence that participation of 30-40 science students in collaboratively developed courses can promote a re-invigorating transformative experience of education for students and faculty involved in otherwise heavily transmissive STEM programs. In particular, collaborative design environments provide conditions supporting "vertical" development of more complex thinking and an expanded worldview. Diverse benefits also accrue to students and faculty partners working as educational co-researchers.

This work was approved by our institutional Ethics Review Board as project \# 112314.

\section{ACKNOWLEDGEMENTS}

We are indebted to Sarah El Kababji, Amritpal Garha, Manpreet Kaur, and Parmveer Mundi for their partnership with us in designing the study, as well as to Ka Ho (Gordon) Lo for his research assistance. We appreciate the feedback and suggestions for improvement to this paper provided by reviewers. 


\section{NOTES ON CONTRIBUTORS}

Cortney Hanna-Benson is an instructional designer and a community collaborator on this project. Cortney's research background focuses primarily on novel educational techniques used to promote student engagement at the post-secondary level. Cortney also specializes in research methods, practicing both qualitative and quantitative techniques.

Shayla Kroeze was an undergraduate student at the time of research but is now working towards a master's in biology with a specialization in environment and sustainability at the University of Western Ontario. Shayla is specifically interested in conservation and the importance of science education and outreach.

Radhika Gandhi was an undergraduate student at the University of Western Ontario and is now working towards a master's in population medicine at the University of Guelph. Her research interests include identifying and improving STEM teaching and learning pedagogies. She aspires to make the field more accessible, inclusive, and equitable for diverse learners.

Tom Haffie is retired from coordinating the first-year biology program at the University of Western Ontario. During the research project described in this article, he was collaborating with Lindi Wahl as a Teaching Fellow to coordinate the Students-as-Partners project in the Faculty of Science.

Lindi Wahl is a professor in mathematics at the University of Western Ontario and a teaching fellow for the Faculty of Science, with interests in engaging and involving undergraduate students in teaching and learning innovations across campus.

\section{REFERENCES}

Bauer, K. W., \& Bennett, J. S. (2003). Alumni perceptions used to assess undergraduate research experience. Journal of Higher Education, 74(2), 210-230.

https://doi.org/10.1353/jhe.2003.0011

Blinne, K. C. (2013). Start with the syllabus: HELPing learners learn through class content collaboration. College Teaching, 61(2), 41-43. https://doi.org/10.1080/87567555.2012.708679

Bovill, C. (2014). An investigation of co-created curricula within higher education in the UK, Ireland and the USA. Innovations in Education and Teaching International, 51(1), 15-25. https://doi.org/10.1080/14703297.2013.770264

Bovill, C., Cook-Sather, A., \& Felten, P. (2011). Students as co-creators of teaching approaches, course design, and curricula: Implications for academic developers. International Journal for Academic Development, 16(2), 133-145. https://doi.org/10.1080/1360144X.2011.568690.

Brubaker, N. D. (2012). Negotiating authority through jointly constructing the course curriculum. Teachers and Teaching: Theory and Practice, 18(2), 159-180. 


\section{https://doi.org/10.1080/13540602.2012.632273}

Calman, L., Brunton, L., \& Molassiotis, A. (2013). Developing longitudinal qualitative designs: Lessons learned and recommendations for health services research. BMC Medical Research Methodology, 13(14), 1-10. https://doi.org/10.1186/1471-2288-13-14

Chen, P. L., Chung, D. S., Crane, A., Hlavach, L., Pierce, J., \& Viall, E. K. (2001). Pedagogy under construction: Learning to teach collaboratively. Journalism and Mass Communication Educator, 56(2), 25-42. https://doi.org/10.1177/107769580105600203

Cockell, J. \& McArthur-Bain, J. (2012) The tenets of appreciative inquiry. In Appreciative inquiry in higher education: A transformative force (1st ed., pp. 13-31). San Francisco, CA: JosseyBass.

Cook-Sather, A. (2014). Student-faculty partnership in explorations of pedagogical practice: A threshold concept in academic development. International Journal for Academic Development, 19(3), 186-198. https://doi.org/10.1080/1360144X.2013.805694

Cooperrider, D. L., Whitney, D., \& Stavros, J. M. (2005). Essential elements of appreciative inquiry. In Appreciative inquiry handbook: For leaders of change (2nd ed., pp. 1--32). San Francisco, CA: Berrett-Koehler.

Cordner, A., Klein, P. T., \& Baiocchi, G. (2012). Co-designing and co-teaching graduate qualitative methods: An innovative ethnographic workshop model. Teaching Sociology, 40(3), 215-226. https://doi.org/10.1177/0092055X12444072

Dawson, P., van der Meer, J., Skalicky, J., \& Cowley, K. (2014). On the effectiveness of supplemental instruction: A systematic review of supplemental instruction and peerassisted study sessions literature between 2001 and 2010. Review of Educational Research, 84(4), 609-639. https://doi.org/10.3102/0034654314540007

Eigel, K., \& Kuhnert, K. (2005). Authentic development: Leadership development level and executive effectiveness. Authentic Leadership Theory and Practice: Origins, Effects and Development, 3, 357-385.

Fassett, D. D. L., \& Warren, D. J. T. (2006). Critical communication pedagogy. SAGE Publishing.

Gilley, B., \& Clarkston, B. (2014). Research and teaching: Collaborative testing: Evidence of learning in a controlled in-class study of undergraduate students. Journal of College Science Teaching, 43(3), 83-91. https://doi.org/10.2505/4/jcst14 $04303 \quad 83$

Glenn, W. J. (2003). Imagine the possibilities: A student-generated unit to inspire creative thought. The English Journal, 92(5), 35-41. https://doi.org/10.2307/3650422

Glynn, S. M., Brickman, P., Armstrong, N., \& Taasoobshirazi, G. (2011). Science motivation questionnaire II: Validation with science majors and nonscience majors. Journal of Research in Science Teaching, 48(10), 1159-1176. https://doi.org/10.1002/tea.20442

Hains, B. J., \& Smith, B. (2012). Student-centered course design: Empowering students to become self-directed learners. Journal of Experiential Education, 35(2), 357-374. https://doi.org/10.1177/105382591203500206

Handelsman, M. M., Briggs, W. L., Sullivan, N., \& Towler, A. (2005). A measure of college student course engagement. Journal of Educational Research, 98(3), 184-192. https://doi.org/10.3200/JOER.98.3.184-192

Healey, M., Flint, A., \& Harrington, K. (2014). Engagement through partnership: Students as partners in learning and teaching in higher education. The Higher Education Academy. 
Retrieved from https://www.advance-he.ac.uk/knowledge-hub/engagement-throughpartnership-students-partners-learning-and-teaching-higher

Held, G., \& Rosenberg, W. (1983). Student-faculty collaboration in teaching college writing. College English, 45(8), 817-823. https://doi.org/10.2307/376700

Hess, G. (2008). Collaborative course design: Not my course, not their course, but our course. Washburn Law Journal, 47(2), 367-387.

Holt, D. G., \& Willard-Holt, C. (1995, April). Efficacy of student-selected curricula. Paper presented at Annual Meeting of the American Educational Research Association, San Francisco, CA. Washington, DC: ERIC Clearhouse.

Hudd, S. S. (2003). Syllabus under construction: Involving students in the creation of class assignments. Teaching Sociology, 31(2), 195-202. https://doi.org/10.2307/3211308

Hufford, T. L. (2011). The role of the undergraduate student in teaching and learning biology. Atlas Journal of Science Education, 1(2), 38-42. https://doi.org/10.5147/ajse.v1i2.73

Jafar, A. (2016). Student engagement, accountability, and empowerment: A case study of collaborative course design. Teaching Sociology, 44(3), 221-232. https://doi.org/10.1177/0092055X16644489

Kay, A. E., Hardy, J., \& Galloway, R. K. (2019). Student use of PeerWise: A multi-institutional, multidisciplinary evaluation. British Journal of Educational Technology, 51(1), 23-35. https://doi.org/10.1111/bjet.12754

Lesnick, A., \& Cook-Sather, A. (2010). Building civic capacity on campus through a radically inclusive teaching and learning initiative. Innovative Higher Education, 35(1), 3-17. https://doi.org/10.1007/s10755-009-9122-3

Maunder, R. E., Cunliffe, M., Galvin, J., Mjali, S., \& Rogers, J. (2013). Listening to student voices: Student researchers exploring undergraduate experiences of university transition. Higher Education, 66, 139-152. https://doi.org/10.1007/s10734-012-9595-3

McCulloch, A. (2009). The student as co-producer: Learning from public administration about the student-university relationship. Studies in Higher Education, 34(2), 171-183. https://doi.org/10.1080/03075070802562857

Mihans, R. J., Long, D., \& Felten, P. (2008). Power and expertise: Student-faculty collaboration in course design and the scholarship of teaching and learning. International Journal for the Scholarship of Teaching and Learning, 2(2). https://doi.org/10.20429/ijsotl.2008.020216

Moreno-Lopez, I. (2005). Sharing power with students: The critical language classroom. Radical Pedagogy. Retrieved from http://radicalpedagogy.icaap.org/content/issue7 2/moreno.html

Petrie, N. (2014). Vertical leadership development - Part 1: Developing leaders for a complex world (White paper). Center for Creative Leadership. Retrieved from http://insights.ccl.org/wp-content/uploads/2015/04/VerticalLeadersPart1.pdf

Petrie, N. (2015). The how-to of vertical leadership development-Part 2: 30 Experts, 3 conditions, and 15 approaches (White paper). Center for Creative Leadership. Retrieved from https://leadershipcoefficient.com/wp-content/uploads/2017/08/White-paper HowTo-of-Vertical-Leadership-part2.pdf

Shor, I. (1997). When students have power: Negotiating authority in a critical pedagogy. College Composition and Communication, 48(4), 588. https://doi.org/10.2307/358469 
Smith, J. A. (1994). Reconstructing selves: An analysis of discrepancies between women's contemporaneous and retrospective accounts of the transition to motherhood. British Journal of Psychology, 85(3), 371-392. https://doi.org/10.1111/j.20448295.1994.tb02530.x

Smith, J. A. (2011). Evaluating the contribution of interpretative phenomenological analysis. Health Psychology Review, 5(1), 9-27. https://doi.org/10.1080/17437199.2010.510659

Smith, J. A., Flowers, P., \& Larkin, M. (2009). Interpretative phenomenological analysis: Theory, method and research. Los Angeles, CA: SAGE Publications.

Smith, J. A., \& Osborn, M. (2008). The aim of interpretative phenomenological analysis. In Qualitative psychology: A practical guide to research methods ( $2^{\text {nd }}$ ed., pp. 53-80), J. A. Smith (ed). Newbury Park, CA: Sage Publications.

Spiers, J., Smith, J. A., \& Drage, M. (2016). A longitudinal interpretative phenomenological analysis of the process of kidney recipients' resolution of complex ambiguities within relationships with their living donors. Journal of Health Psychology, 21(11), 2600-2611. https://doi.org/10.1177/1359105315581070

Taylor, C. A., \& Bovill, C. (2018). Towards an ecology of participation: Process philosophy and co-creation of higher education curricula. European Educational Research Journal, 17(1), 112-128. https://doi.org/10.1177/1474904117704102

Thomson, R., Martin, J. L., \& Sharples, S. (2017). The experience of couples being given an oxygen concentrator to use at home: A longitudinal interpretative phenomenological analysis. Journal of Health Psychology, 22(6), 798-810. https://doi.org/10.1177/1359105315615932

Vickrey, T., Rosploch, K., Rahmanian, R., Pilarz, M., \& Stains, M. (2015). Research-based implementation of peer instruction: A literature review. CBE Life Sciences Education, 14(1), 1-11. https://doi.org/10.1187/cbe.14-11-0198 